\title{
Effect of Yttrium Addition on Corrosion Resistance of Zr-based Bulk Metallic Glasses in NaCl Solution
}

\author{
Liusi Yu ${ }^{1}$, Junlei Tang ${ }^{1, *}, J_{i c h a o}$ Qiao $^{2}, H u$ Wang $^{3}$, Yingying Wang ${ }^{1}$, Mihai Apreutesei ${ }^{4}$, \\ Mohammad Chamas ${ }^{1}$, Ming Duan ${ }^{1}$ \\ ${ }^{1}$ School of Chemistry and Chemical Engineering, Southwest Petroleum University, Chengdu 610500, \\ P.R. China \\ ${ }^{2}$ School of Mechanics, Civil Engineering and Architecture, Northwestern Polytechnical University, \\ Xi'an 710072, P.R. China \\ ${ }^{3}$ School of Material Science and Engineering, Southwest Petroleum University, Chengdu 610500, P.R. \\ China \\ ${ }^{4}$ Université de Lyon, Institut des Nanotechnologies de Lyon INL-UMR5270, CNRS, Ecole Centrale \\ de Lyon, Ecully F-69134, France \\ *E-mail: tangjunlei@126.com
}

doi: $10.20964 / 2017.07 .47$

Received: 11 April 2017 / Accepted: 2 May 2017 / Published: 12 June 2017

\begin{abstract}
This study investigated the effect of yttrium addition on the electrochemical properties of $\left(\mathrm{Zr}_{58} \mathrm{Nb}_{3} \mathrm{Cu}_{16} \mathrm{Ni}_{13} \mathrm{Al}_{10}\right)_{100-\mathrm{x}} \mathrm{Y}_{\mathrm{x}}(\mathrm{x}=0,0.5,2.5$ at.\%) bulk metallic glasses in $3.5 \mathrm{wt} . \% \mathrm{NaCl}$ solution. Electrochemical measurements, scanning electron microscopy (SEM), energy dispersive spectroscopy (EDS) and X-ray photoelectron spectroscopy (XPS) were employed. Zr-based bulk metallic glasses exhibited good corrosion resistance. It was ascribed to the formation of a protective passive film which was composed of $\mathrm{ZrO}_{2}, \mathrm{Al}_{2} \mathrm{O}_{3}$ and a few oxides of other alloying elements, i.e. $\mathrm{Y}_{2} \mathrm{O}_{3}$. However, the breakdown potential decreased due to the addition of yttrium. Electrochemical impedance spectroscopy (EIS) suggested that yttrium addition could decrease the charge transfer resistance. That is, the addition of yttrium was harmful to the corrosion resistance of this $\mathrm{Zr}$-based bulk metallic glass in $3.5 \mathrm{wt} . \% \mathrm{NaCl}$ solution. It was attributed to the precipitation of $\mathrm{Cu}-\mathrm{Y}$ richly quasi-crystal phase owing to yttrium addition, which caused inhomogeneous distribution of copper and yttrium in microstructure.
\end{abstract}

Keywords: Zr-based bulk metallic glasses; Pitting corrosion resistance; Yttrium; Electrochemical measurements; XPS 
(C) 2017 The Authors. Published by ESG (www.electrochemsci.org). This article is an open access article distributed under the terms and conditions of the Creative Commons Attribution license (http://creativecommons.org/licenses/by/4.0/). 